\title{
Le centre culturel Tjibaou ou les difficultés d'incarner une identité néocalédonienne en devenir
}

\section{Quitterie Puel et Fabien Van Geert}

\section{(2) OpenEdition}

\section{Journals}

Édition électronique

URL : https://journals.openedition.org/iss/3355

DOI : 10.4000/iss.3355

ISSN : 2306-4161

Éditeur

ICOM - International Council of Museums

\section{Édition imprimée}

Date de publication : 18 décembre 2021

Pagination : 118-133

ISBN : 978-92-9012-446-7

ISSN : 2309-1290

\section{Référence électronique}

Quitterie Puel et Fabien Van Geert, « Le centre culturel Tjibaou ou les difficultés d'incarner une identité néocalédonienne en devenir », ICOFOM Study Series [En ligne], 49-1 | 2021, mis en ligne le 18 décembre 2021, consulté le 08 janvier 2022. URL : http://journals.openedition.org/iss/3355 ; DOI : https:// doi.org/10.4000/iss.3355 


\section{Le centre culturel Tjibaou ou les difficultés d'incarner \\ une identité néocalédonienne en devenir}

\section{Quitterie Puel}

Chercheuse indépendante, Perth

\section{Fabien Van Geert}

Université Sorbonne Nouvelle, Paris

\section{RÉSUMÉ :}

Parce qu'il participe de la création de références culturelles et d'un imaginaire collectif, le musée permet la diffusion d'un sentiment d'appartenance nationale au sein de la population. Le centre culturel Tjibaou, au moment de sa construction, avait pour mission de valoriser la culture kanak. Depuis l'Accord de Nouméa, l'identité néo-calédonienne est en pleine construction dans l'archipel et le centre a progressivement eu pour mission de soutenir ce projet de société. Cet établissement 
offre donc un éclairage à la fois unique et contemporain sur le rôle des institutions culturelles dans la construction des identités nationales. Dans cet article, nous observons les stratégies mises en place par le centre pour accomplir ses missions ainsi que les obstacles qui fragilisent aujourd'hui sa légitimité en tant qu'acteur du " destin commun ».

Mots clés: Centre culturel Tjibaou, Nouvelle-Calédonie, Pacifique, identité, musées

ABSTRACT:

As they participate in the creation of cultural references and collective imagination, museums reinforce the feeling of national belonging within the population. When it was built, the Centre Culturel Tjibaou's main mission was to promote Kanak culture. Since the Accord de Nouméa, Caledonian identity is under process and the Centre's missions have changed. From the promotion of Kanak culture, it is now also in charge of supporting a societal project for all the island. The Centre offers then a contemporary and unique insight on the role of cultural institutions in the nation-building process. In this paper, we consider the Centre's multiple strategies to achieve its missions as well as the impediments which undermine its legitimacy as a leading cultural institution of the destin commun.

Key words: Centre Culturel Tjibaou, New Caledonia, Pacific, Identity, Museums.

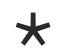

En politique, rien n'est possible sans références culturelles, sans la mobilisation d'un imaginaire collectif. Comme cela a été largement démontré, la conformation et la légitimation des Etats-Nations aux 19e et 20e siècles ont en effet été accompagnées par l'écriture d'un récit national, tout particulièrement grâce aux musées dont l'arrangement des collections devait permettre l'inculcation d'un sentiment national parmi la population (Kaplan, 1994; Macdonald \& Fyfe, 1996). C'est le cas des « colonies de peuplement » où les différentes vagues migratoires en provenance du vieux continent ont pris le contrôle économique, politique, social et culturel de ces pays lors de leur indépendance, aux dépens des peuples autochtones. Les musées y incarnèrent dès lors l'idée d'une nouvelle nation, définie par les descendants des colons, en exposant les résultats des explorations scientifiques vers l'intérieur des territoires, ainsi que les cultures autochtones « découvertes » à la même occasion (Bergeron, 2019). Depuis les années 1970 cependant, les exigences de reconnaissance politique formulées par ces marginalisés de la construction nationale ont provoqué un renouveau 
de leur représentation au sein des musées. Désormais perçus comme partie intégrante de la nation au sein des discours multiculturels, de nouvelles institutions nationales vont être créées dès la fin des années 1980 afin d'exposer de nouveaux mythes et symboles nationaux (Van Geert, 2020).

En Océanie, ce processus de transformation muséale est bien connu en Australie et en Nouvelle-Zélande (Morphy, 2017; McCarthy, 2018). Au-delà de ces deux pays, la réalité de l'immense zone océanienne est néanmoins très hétérogène, conséquente d'une décolonisation tardive et en partie finalisée, qui donne lieu à des approches muséales particulières parfois regroupées sous le concept de «muséologie du Pacifique ( Healy \& Witcomb, 2006). Dans ce contexte, la Nouvelle-Calédonie, ex- «colonie de peuplement », désormais collectivité sui generis française située à plus de 16000 kilomètres de la métropole apparaît comme intéressante. Ce territoire présente en effet un processus politique particulier depuis les «Evénements » (1984-1988) qui ont vu s'affronter les descendants des colons européens, majoritairement favorables au maintien de l'archipel dans le giron français, et les Kanak, populations mélanésiennes spoliées de leurs terres et exclues pendant plus d'un siècle de la gouvernance de ce territoire dont ils réclamaient alors l'indépendance. Afin d'apaiser ces tensions, la signature des Accords de Matignon en 1988 entre le leader indépendantiste Jean-Marie Tjibaou et le loyaliste Jacques Lafleur, sous l'égide du gouvernement français de Michel Rocard, prévoyait la tenue d'un référendum sur le futur de l'archipel, en 1998. Cette période de dix ans devait permettre un rééquilibrage économique et politique du territoire en faveur des Kanak, accompagné d'une plus grande reconnaissance culturelle de cette population, au travers notamment de la création de l'Agence de développement de la culture kanak (ADCK) censée prolonger les efforts du festival Mélanésia 2000, tenu en 1975 sous l'égide de Tjibaou. Repoussant la tenue du référendum entre 2014 et 2018, l'Accord de Nouméa de 1998 prolongea cette dynamique en tentant de favoriser la construction d'une citoyenneté néo-calédonienne basée sur l'idée de « communauté de destin partagé » entre les différentes communautés de l'île, moyennant la création de symboles et l'écriture d'un récit national (Sand, Bolé \& Ouetcho, 2003). Cette notion de « destin commun » désigne la nécessité pour le peuple d'origine, les Kanak, et les autres ethnies de l'archipel de constituer les bases d'une citoyenneté commune et ce, quel que soit l'avenir politique de la Nouvelle-Calédonie.

En tant que lieux symboliques d'une nation en devenir, les musées néo-calédoniens ont joué un rôle de premier plan dans ce processus, à l'image du centre culturel Tjibaou. Profitant du contexte de célébration de son vingtième anniversaire en 2018, cet article se propose de revenir sur son histoire, ainsi que sur la modification de ses missions, parallèlement aux mutations des débats politiques en Nouvelle-Calédonie, en se basant sur la littérature existante, des extraits de presse, mais aussi des observations et entretiens réalisés in situ en 2018. En souhaitant apporter un regard original sur le rôle politique des musées dans la définition des identités, ce texte s'intéresse tout particulièrement aux 
manières dont les actions du centre contribuent à la création de mythes originels d'une nation en devenir. Quelles représentations y trouve-t-on des Kanak et des autres communautés de l'île? Quelle place y est laissée au métissage entre les différentes populations de ce territoire, dont certaines réclament désormais leur place dans le débat politique après plus de vingt ans de polarisation politique entre Kanak et descendants de colons? Comment traiter ces enjeux alors mềme qu'une historiographie de l'histoire coloniale de la Nouvelle-Calédonie a mis longuement à émerger (Trépied, 2013) et que la France peine elle-même à aborder son histoire coloniale? Alors que les deux premières consultations sur l'accession à la pleine souveraineté de la Nouvelle-Calédonie en 2018 et 2020 ont donné la victoire à son maintien dans la France, ces enjeux de construction identitaire s'avèrent loin d'être réglés, en faisant de cet établissement culturel le cœur d'enjeux symboliques de premier ordre.

\section{L'origine et la création du centre culturel Tjibaou}

L'élan menant à la création du centre culturel Tjibaou doit être cherché dans la volonté de rééquilibrage du territoire en faveur des Kanak à la suite de la signature des Accords de Matignon. Ces derniers prévoient en effet une meilleure reconnaissance de leur culture et de leur patrimoine en assurant "l'accès de tous à l'information et à la culture » pour " permettre l'expression et l'épanouissement sous toutes ses formes de la personnalité mélanésienne » (République française, 1988). Dans ce contexte, Jean-Marie Tjibaou fait inscrire la création d'un centre culturel kanak à Nouméa, à majorité européenne et anti-indépendantiste, en vue d'y symboliser le rééquilibrage culturel et de permettre à la population de la ville et du territoire de mieux comprendre les arts et traditions kanak. Son assassinat en 1989, perpétré par un indépendantiste radicalement opposé aux Accords, provoque une vive émotion dans le monde politique de l'époque et donne une impulsion nouvelle à la concrétisation de ce projet.

Très rapidement, dès l'automne 1990, un concours d'architecture présidé par Marie-Claude - veuve de Jean-Marie Tjibaou et présidente de l'ADCK -, et le président de la République, François Mitterrand, est lancé afin de choisir le futur architecte de ce centre devant accueillir l'ADCK. Sur les cent-soixante-dix maquettes présentées, c'est celle de l'italien Renzo Piano qui l'emporte, fruit d'une réflexion menée avec l'ethnologue français Alban Bensa, spécialiste de la culture kanak. Le projet final donne à voir une image de la culture kanak pleinement inscrite dans la modernité, notamment au travers des dix cases qui constituent la structure centrale du centre et qui ne ressemblent pas aux cases traditionnelles kanak. De forme arrondie, les cases imaginées par les deux hommes ne sont pas fermées sur le dessus mais s'élèvent au contraire vers le ciel. Opaques et fournies vers le bas elles se dévêtissent progressivement pour ne laisser qu'apparaître leur membrure au sommet. Ce design inachevé porte en lui-même un message : Renzo Piano parlait de celles-ci comme d'un 
«souvenir ouvert sur un rêve d'avenir » (cité dans Agence de développement de la culture kanak, 1998).

Son architecture novatrice est en effet interprétée par le jury comme prolongeant la pensée de Tjibaou pour qui politique et culture sont étroitement liées. Selon ce dernier, l'indépendance politique du peuple kanak passe en effet par une expression unifiée et moderne de sa culture, impliquant d'exprimer cette dernière dans sa contemporanéité (Graille, 2015). En optant pour une architecture moderne et innovante, ce bâtiment souhaite ainsi poser la culture kanak « au-delà d'elle-même » en l'authentifiant « moins au nom du passé qu'en référence à l'avenir » (Bensa, 2000).

En mars 1995, le premier arbre est planté sur le site du futur centre. MarieClaude Tjibaou édicte alors ses missions officielles (Tjibaou, 1995) :

- Affirmer la culture kanak dans son patrimoine, son actualité et sa création ;

- Situer la culture kanak comme référence dans son pays tant pour la société kanak que pour l'ensemble des communautés de Nouvelle-Calédonie auxquelles il est proposé une passerelle ;

- Fonder sur cette base les éléments de références culturelles communes où pourra s'enraciner une création artistique contemporaine appelée à s'inscrire résolument dans le monde océanien;

- Donner une image «moteur » du pays par la qualité de son architecture et de ses actions, il sera l'emblème de la Nouvelle-Calédonie et contribuera aussi au développement du tourisme global du pays.

Au cours des trois années qui précèdent l'ouverture du centre, des réactions d'opposition ainsi qu'une certaine inquiétude émergent cependant au sein d'autres communautés de l'archipel (Kasarhérou, 1999). Dans une lettre ouverte adressée au Haut-Commissaire de la République en Nouvelle-Calédonie, l'Association La Nouvelle dénonce ainsi une "ségrégation culturelle (...) entretenue au profit d'une infime minorité » (cité par Graille, 2015). Cette société des descendants de bagnards et des personnes issues de la colonisation pénale ajoute par ailleurs qu'un « centre culturel de 5,8 milliards de francs sera achevé à la fin de l'année 1997 à Tina sans qu'à ce jour la place des populations non kanak de la Nouvelle-Calédonie dans son fonctionnement n'ait été clairement définie » (cité par Graille, 2015). Si la communauté blanche se positionne clairement, les autres communautés se font quant à elles plus discrètes et semblent moins concernées par l'ouverture du centre. À cette époque pourtant, il existe des amicales, des associations et même des foyers culturels vietnamiens, chinois ou wallisiens où les individus se rassemblent pour parler leur langue natale et célébrer leurs traditions (Graille, 2015). A la veille de l'ouverture de l'institution, le paysage social calédonien apparait donc comme composé de communautés qui se mélangent peu, et dont certaines voient le centre comme une menace (Kasarhérou, 1999). 
L'établissement est néanmoins inauguré les 4 et 5 mai 1998, en même temps qu'est signé l'Accord de Nouméa qui, tout en reconnaissant l'identité kanak comme fondamentale, évoque la nécessité d'une « citoyenneté calédonienne ». Cette notion veut faire une large place aux colons européens, aux communautés venues d'Asie en qualité de main d'œuvre dès la fin du 19e siècle, mais également à celles venues du Pacifique lors du boom du nickel à la fin des années 1960 (Sand, Bolé \& Ouetcho, 2003). Les attentes de cet accord se retrouvent de manière explicite dans le discours de Lionel Jospin lors de l'inauguration du centre, appelé à constituer l'un des principaux symboles de cette construction nationale. Il affirme en effet que « ce rassemblement illustre la double vocation du centre, témoigner de l'identité kanak, et offrir un lieu de dialogue et d'échange avec toutes les cultures océaniennes », avant d'ajouter que "pleinement reconnue, la culture kanak peut s'ouvrir à d'autres. Le dialogue des cultures devient ainsi un moyen de construire la paix » (République Française, 1998). Lors de cette inauguration, Marie-Claude Tjibaou rappelle néanmoins que la culture kanak doit constituer le pilier central de l'Accord de Nouméa ainsi que la base pour la construction d'un destin commun. En effet, selon elle, « offrir ainsi le patrimoine kanak en héritage culturel à l'ensemble de la population de Nouvelle-Calédonie et développer la création artistique, c'est permettre aux Kanak, anciens et jeunes, de retrouver avec fierté leurs racines... ${ }^{1}$.

De par ses objectifs, l'accord de Nouméa ouvre une brèche (Graille, 2018) dans un contexte identitaire particulier en exigeant de communautés, qui ne partagent pas la même vision du passé, qu'elles co-créent ensemble une communauté de destin et donc une citoyenneté calédonienne (Sand, Bolé \& Ouetcho, 2003). Symbole et point de départ de ces accords, l'ouverture du centre va donc catalyser les tensions et les aspirations de l'époque en restant à la fois un lieu en l'honneur des Kanak tout en devenant un acteur ainsi qu'un espace de création symbolique du destin commun. Pris entre ces deux approches, les missions du centre évoluent, ce qui rend paradoxalement son rôle et son identité plus confus.

\section{De la mise à l’honneur des Kanaks à l'incarnant du destin commun}

Dans ce contexte particulier, en 2008, pour la célébration des vingt ans des Accords de Matignon, est inaugurée une grande exposition d'art contemporain intitulée «Si y’a pas toi, y'a pas moi ». Ce slogan, inventé en 2007 par l'animateur de la radio indépendantiste Radio Djido « Kiki Karé », célèbre la diversité culturelle de la Nouvelle-Calédonie. L'exposition se construit autour de cette philosophie avec comme point d'orgue, la célèbre poignée de main entre Jean-Marie Tjibaou et Jacques Lafleur. Cette dernière y est érigée comme marqueur de l'avènement de la paix dans une période jusque-là troublée par les

I. https://www.gouvernement.fr/partage/Ior4o-les-chefs-coutumiers-donnent-son-nom-au-centreculturel-tjibaou. Page consultée le 26 mai 202I. 
violences identitaires, mais aussi comme symbole d'une relation apaisée entre les différentes communautés de l'archipel. On retrouve cette même volonté lors de la célébration des dix ans de la création du centre, au cours de laquelle toutes les communautés du Pacifique sont invitées à planter des arbres sur l'aire coutumière Mwâ Kââ (Graille, 2018). L'aire coutumière est un espace situé à l'extérieur du centre où s'établit la coutume qui est, dans la tradition kanak, la condition d'un séjour réussi en terre kanak. A l'image de ces arbres, le message est clair : même si elles sont différentes, ces communautés doivent grandir ensemble sur le sol calédonien.

En 2012, dans le cadre du transfert de compétence prévu par l'Accord de Nouméa, le Haut-Commissaire de la République déplore néanmoins «l'absence du sentiment d'appartenance à une même société - ciment de la cohésion sociale » de la Nouvelle-Calédonie (cité dans Dubois, 2014). Pour endiguer ce phénomène, il préconise notamment « la réduction des inégalités, l'affirmation de repères identitaires et le partage de valeurs sociétales » (Dubois, 2014). Dans ce contexte, le centre a désormais pour missions officielles de :

- rechercher, collecter, valoriser et promouvoir le patrimoine culturel kanak;

- mettre en œuvre et développer la création artistique kanak ;

- susciter l'émergence de pratiques et de références culturelles communes à la Nouvelle-Calédonie ;

- être un pôle de rayonnement et d'échanges régionaux et internationaux (Agence de développement de la culture kanak, 2017)

Même si la valorisation de la culture kanak constitue toujours le cour de ses missions, le rôle du centre vis-à-vis des autres communautés est désormais explicite. La programmation du centre prend alors un tournant nouveau en accordant une place plus large à ces dernières lors de ses expositions et ses activités. En 2015, il accueille ainsi « La fête du toka à Tanna », une exposition photographique de Pierre-Alain Pantz qui rend hommage aux célébrations qui ont lieu entre les nakamal de Tanna au Vanuatu. La même année, "Calédoun » retrace l'histoire des déportés algériens en Nouvelle-Calédonie, sous le commissariat de Christophe Sand. Entre 2018 et 2019, «Qu'avons-nous en commun » invite les spectateurs, grâce aux œuvres de six artistes océaniens, à réfléchir à ce qui les rassemble et à ce que signifie « travailler ensemble » lorsque l'on vient de cultures différentes. Enfin, la Grande Case du Sud du centre est rénovée en janvier 2021. Comme le déclare alors Emmanuel Tjibaou, directeur du centre, "renouveler la paille [de cette case] est un moyen de renouveler les alliances entre les différentes communautés du Pacifique » (Antic-Martin et al., 2021), en les invitant à déposer des objets traditionnels de leur culture d'origine à l'intérieur de cette case.

Si la programmation se diversifie le centre peine néanmoins à toucher son public. Si en 2008, il enregistre plus de 98000 entrées (ADCK-Centre Culturel 
Tjibaou, 2016), grâce notamment à l'exposition « Si y'a pas toi, y'a pas moi », seules quelques expositions vont réussir à toucher par la suite un large public. C'est le cas de "Kanak, l'art est une parole », tenue entre 2013 et 2014, qui attire plus de 32000 visiteurs (soit plus de $10 \%$ de la population locale). Perçue comme une continuité de l'exposition emblématique «De jade et de nacre » réalisée en $1990^{2}$, cette exposition commissionnée par Emmanuel Kasarhérou et Roger Boulay, présente les résultats de «l'Inventaire du patrimoine kanak dispersé », au travers de plus de cent objets prêtés par des musées internationaux (Bertin, 2019)3. Outre cette exposition, le nombre de visiteurs du centre stagne et ne dépasse pas les 75434 en 2016 (ADCK-Centre Culturel Tjibaou, 2016).

Cette situation s'explique en partie par les restrictions budgétaires que connaît l'institution (ainsi que l'ensemble des collectivités calédoniennes). En 2016, le budget du centre est réduit de 40 millions de francs Pacifique ${ }^{4}$, impliquant une nette diminution de sa programmation (Nollet, 2016). En 2018, ce chiffre s'aggrave encore, avec le retrait de la Province des îles qui entraine une réduction supplémentaire de 26 millions de francs Pacifique (ADCK-Centre Culturel Tjibaou, 2016), alors même que les frais de conservation et de restauration de son bâtiment emblématique restent intacts. D'autres raisons permettent néanmoins d'expliquer la difficulté du centre à trouver son public, mais aussi à constituer un symbole de l'identité calédonienne. C'est ce que nous allons voir dans la prochaine partie.

\section{Le centre culturel Tjibaou, un espace trop « passionné ॥ pour construire la Calédonie de demain ?}

Au-delà des complexités budgétaires que nous venons d'évoquer, certaines raisons structurelles permettent d'expliquer la faible proportion du public local dans le centre, dont le nom ainsi que l'histoire demeurent, pour beaucoup de Calédoniens, synonymes de tabou, de douleur et de violence. Rappelons qu'il s'agit en effet d'un projet métropolitain partiellement financé par l'État français. Ce financement se fait via le budget alloué à la Nouvelle-Calédonie qui perçoit la dotation de transfert. Le centre, en tant qu'établissement de la Nouvelle-Calédonie, est financé majoritairement par le gouvernement local à hauteur de $80 \%$. Les provinces Nord, Sud et des 1̂les interviennent à hauteur d'environ $8 \%$ et le centre génère environ $12 \%$ de ses recettes propres (Entretien

\footnotetext{
2. Dans les années I980, Roger Boulay, responsable des collections océaniennes du musée des Arts d'Afrique et d'Océanie de Paris est chargé de «l'Inventaire du patrimoine Kanak dispersé », souhaité par Tjibaou, visant à répertorier les objets kanaks conservés dans les musées du monde entier. La première phase de cette enquête permit notamment de définir un ensemble de collections, souvent inédites, qui constituèrent la base de l'exposition itinérante « De Jade et de Nacre : patrimoine artistique kanak », présentée au musée territorial de Nouvelle-Calédonie à Nouméa, en I990, puis au musée des Arts d'Afrique et d'Océanie de Paris.

3. Notons que cette exposition a été présentée auparavant, en 20I2, au musée du quai Branly à Paris, dont Kasarhérou est depuis devenu le directeur.
}

4. L'équivalent de près de 334 ooo euros. 
réalisé avec Guillaume Soulard, mai 2020). Le projet a en outre été inscrit dans les Grands Travaux de la République ayant pour ambition d'œuvrer pour le rayonnement de la France dans le domaine culturel. Il est, parmi tous les Grands Travaux, le seul qui ne soit pas en France hexagonale. Aussi, en 1988, lorsque ce projet est né, il a surtout pour ambition de combler l'écart entre les aspirations contradictoires du gouvernement français et des Kanak qui revendiquent alors leur indépendance (Message, 2006). Sa réalisation est donc perçue comme « un geste » de la France envers la Nouvelle-Calédonie. Cette influence française se retrouve aussi dans l'architecture du lieu. Brown s'interroge ainsi sur l'intention de l'architecte Renzo Piano quand il propose une version moderne et «démocratique » des cases kanak traditionnelles. Vouloir les moderniser, n'est-ce pas une manière de les européaniser? (Brown, 2002). De son côté l'ethnologue Jean Guiart fustige la configuration interne du centre qui obéit aux standards métropolitains des lieux culturels. Dans les deux cas, c'est la présence française qui est pointée du doigt et le fait que le centre impose une « conception étrangère de la culture » au peuple kanak (Guiart, 1996). L'étroitesse des relations entre le centre et le gouvernement français interroge en outre la capacité, voire la légitimité d'une telle institution à produire des symboles de la citoyenneté calédonienne. De fait, vouloir faire du centre l'un des acteurs du destin commun, n'est-ce pas une façon de perpétuer une forme de paternalisme entre la France et la Nouvelle-Calédonie?

Au-delà de cet aspect politique, rappelons que la création du centre a suscité également des tensions parmi les Kanak. Ce projet est alors loin de faire l'unanimité : beaucoup de Kanak se sont opposés à la construction du centre à Nouméa, ville jugée trop européenne, et auraient préféré qu’il soit construit dans le Nord du territoire, fief de Tjibaou. Le nom donné au centre a lui aussi provoqué de nombreux désaccords quant à sa légitimité du fait de l'appartenance de Tjibaou à un clan particulier (Dussy, 2003). Aujourd'hui encore, le poids du passé rebute une partie de la société calédonienne qui rechigne à fréquenter ce lieu. Marguerite Martin, cheffe du service Accueil et Jeune Public au centre en 2018 résume ainsi la situation :

«Un jeune Caldoche ne va pas vouloir aller dans un bâtiment créé pour les Kanak ou les touristes. Un jeune Kanak des îles ne va pas vouloir aller dans un bâtiment construit par les Kanak du nord (du fait du nom Tjibaou). Ce n'est pas une véritable barrière mais c'est la barrière que les gens se mettent. Les jeunes Européens n'auront aucune réticence à venir ici. Pour un jeune Caldoche, le centre a une signification bien différente de celle du Kanak ou de l'Européen. A un moment donné, il faudrait réussir à désacraliser l'outil pour que les gens viennent. Mais, en même temps, si on le désacralise, on en fait n'importe quoi. »

(Entretien réalisé avec Marguerite Martin, avril 2018) 
Plus largement, le centre peine depuis sa création à faire venir le public kanak, du fait de son relatif éloignement de la ville, de sa difficulté d'accès (le centre se situe à plus de sept kilomètres du centre-ville et est difficilement accessible en transports en commun), de son prix d'entrée (500 francs CFP soit un peu plus de 4 euros), mais aussi surtout de l'écart progressivement creusé entre ce dernier et l'ADCK, dont il est pourtant le siège. Nicole Waia, journaliste et militante de l'Union calédonienne, rappelle ainsi, en 2008, le rapport complexe que les Kanak entretiennent avec le centre:

«Pour les Kanak, le CCT [centre culturel Tjibaou] c'est un grand truc alors que l'ADCK c'est l'Agence de Développement de la Culture Kanak, ce qui veut dire quelque chose. Le CCT n'est que l'outil de l'ADCK et non l'inverse. Or, c'est lui que l'on met systématiquement en avant par rapport à l'ADCK et l'on fait fi d'elle. Cela explique en partie le désintérêt des Kanak vis-à-vis du CCT et leur peu d'empressement à se l'approprier. Peut-être faudrait-il dissocier l'ADCK du CCT, en tout cas leurs missions, et faire en sorte que ces deux entités se partagent les tâches [...]. Il faut que l'on laisse au CCT le rôle pour lequel il est fait, celui je le répète d'être l'outil de l'Agence de Développement de la Culture Kanak, et j’insiste sur chacun des mots qui définissent cette agence. » (Waïa, 2008)

\section{9}

Au-delà de ces complexités originelles du centre, notons que d'autres institutions se restructurent également aujourd'hui afin de tenter d'incarner l'esprit de l'Accord de Nouméa. Créé en 1971, le musée de la Nouvelle-Calédonie a ainsi longtemps été consacré à l'archéologie et à l'ethnologie de l'archipel en se centrant essentiellement sur la population et les objets kanak. Cette muséologie est aujourd'hui jugée trop passéiste (Graille, 2018) et l'établissement est actuellement en cours de rénovation. Le nouveau projet vise notamment à offrir une vision plus large de la société calédonienne, au travers notamment de l'intégration des différentes communautés dans le parcours muséologique. L'ancienne architecture du musée doit être, elle aussi, modifiée, pour s'éloigner des standards européens et mieux s'ancrer dans la tradition locale. Le bâtiment d'origine, de couleur blanche et sans particularités architecturales, sera rénové dans un style plus art déco faisant appel à des matériaux produits localement (Bertin, 2020).

À l'image de la rénovation de ce musée, le paysage culturel calédonien a beaucoup changé depuis l'inauguration du centre. L'archipel s'est doté de structures modernes, moins investies symboliquement, qui attirent aujourd'hui une population plus jeune. C'est le cas du centre culturel du Mont Dore, créé en 2002, dont la programmation culturelle foisonnante (pièces de théâtre, festival de films indépendants, ciné-débats etc.) s’adresse à un public varié. En 
juin 2021, s'est y ainsi tenue la pièce de théâtre « La fantastique aventure du bateau nommé île de Lumière », qui entre en résonance avec l'exposition « L'Ile de Lumière, l>engagement humanitaire d`un navire calédonien » présentée en aout 2019 au musée maritime de Nouvelle-Calédonie. «L'île de lumière » est le nom du cargo affrété par Bernard Kouchner dans les années 1970 pour venir en aide aux vietnamiens qui fuyaient le régime communiste. Ce navire est parti du port de Nouméa « avec un équipage essentiellement constitué de calédoniens que rien ne prédestinait à une telle aventure » (Musée maritime de la Nouvelle-Calédonie, 2019). En mettant en lumière des évènements passés de ce type, ces institutions participent sans aucun doute à l'écriture du nouveau récit national calédonien.

Si le centre culturel du Mont Dore peut jouir d'une telle variété au niveau de la programmation, c'est notamment parce qu'il s'agit d'une structure municipale aux coûts de fonctionnement relativement faibles. Les artistes y sont rémunérés à la recette, ce qui permet à la direction de jouer la carte de l'éclectisme et de l'audace, sans pour autant prendre trop de risques. Le fonctionnement du centre culturel du Mont Dore est en sens radicalement différent de celui du centre culturel Tjibaou comme nous l'explique Gregory Louzier, l'actuel directeur :

"On est une petite équipe, très soudée, on est tous jeunes et on est passionnés. Ce qu'il faut savoir c'est que cet outil est chouette parce qu'il est fonctionnel, on arrive, on allume la lumière, on n'a pas de grosse contrainte. Tjibaou, ils ont des coûts énormes et ils sont embêtés. Nous n'avons pas besoin de mettre un vigile. Ce n'a pas les mêmes coûts, c'est très fonctionnel, on ouvre, on embête personne. On a une place à part dans le monde la culture parce que le monde de la culture n'est pas adapté au monde des fonctionnaires et de l'administration. " (Entretien réalisé avec Grégory Louzier, avril 2018)

Alors que la Nouvelle-Calédonie construit aujourd'hui un modèle culturel qui lui est propre, une structure comme celle du centre culturel Tjibaou ne serait-elle plus adaptée ? Encouragée par l'existence d'institutions comme le Mont Dore (mais aussi le Rex de Nouméa ou le Théâtre de l'Ile), une nouvelle génération calédonienne, plus métissée et moins affectée par les clivages identitaires que ses prédécesseurs, créé en effet aujourd'hui les symboles du destin commun. Dans un entretien accordé à la revue Mwa Vée, la danseuse Diane Lise Da Ros revient sur ces nouvelles formes d'expression qui émanent de la nouvelle génération dont le rapport au passé plus décomplexé libère en quelque sorte la création artistique :

"Une nouvelle génération a vu le jour. C'est ainsi que l'on assiste ces derniéres années à l'émergence de jeunes danseurs et chorégraphes 
décomplexés par rapport à leur créativité et à leurs créations. Certains d'entre eux font même le lien entre formes anciennes et formes nouvelles de la danse. On retrouve notamment cette attitude dans la danse urbaine, le hip-hop en particulier... » (Da Ros, 2010)

Le recours aux pratiques coutumières traditionnelles apparaît en effet comme un élément central dans le processus de construction de cette identité calédonienne. Paul Barri, membre de l'association indonésienne de Nouvelle-Calédonie et danseur de hip-hop détaille ce lien entre formes anciennes et formes nouvelle dans le milieu de la danse en Calédonie :

\begin{abstract}
"Le mouvement urbain existe en Calédonie et il est structuré autour d'associations. Il a une façon de faire, il a une identité qui lui est propre. Le fait de faire des temps de parole, des temps de palabre, le fait de faire la coutume (...) c'est trés océanien de faire ça, on représente la case et on échange. Il faut voir le mouvement hip hop comme une case avec des poteaux, c'est important de se parler.»

(Entretien réalisé avec Pau Barri, avril 2018)
\end{abstract}

99

Alors que ces institutions culturelles contribuent efficacement à donner un souffle nouveau à la création contemporaine en Nouvelle-Calédonie, la place du centre dans le paysage culturel calédonien semble de plus en plus floue. En 2009, le centre produisait ainsi le festival Emergence qui avait pour but « d'affirmer son ouverture vis-à-vis de la scène artistique locale et de la dynami$\operatorname{ser}^{5} »$. Ce festival cherchait à favoriser la rencontre entre les formes de danses traditionnelles et contemporaines et permettait aussi aux lauréats d'intégrer la programmation du centre. Il s'est cependant arrêté en 2011 et ces initiatives se sont aujourd'hui déplacées du côté du Rex ou du centre culturel du Mont Dore. Dans ce contexte, la question du futur du centre se pose bien entendu, ainsi que son rôle dans un pays qui pourrait bien devenir indépendant, sur le court ou le moyen terme. Cette question, voire cette incertitude est actuellement bien présente et se ressent dans certaines de ses activités, comme nous allons le voir.

\title{
Conclusions
}

Les multiples difficultés que nous venons d'évoquer permettent sans aucun doute d'expliquer le peu de célébration autour du vingtième anniversaire du centre - et donc de l'Accord de Nouméa -, en 2018. Ce soir-là a en effet unique-

5. http://www.adck.nc/spectacles/programmation/307-les-nuits-emergence. Page consultée le ro juin 2O2I. 
ment lieu le spectacle «Pilou Pilou » auquel participent six troupes océaniennes. Parmi elles, quatre sont calédoniennes et proviennent de différentes parties de l'archipel. Les deux autres sont wallisienne et tahitienne. Au moment du spectacle, la majorité propose des danses traditionnelles appartenant à leurs répertoires respectifs tandis que le Saian Breaker Crew, une jeune troupe de danseurs originaires de Nouméa, propose une chorégraphie moderne inspirée notamment du hip-hop. À la fin de la cérémonie, les danseurs et spectateurs se sont réunis pour présenter la danse de la case qui clôture traditionnellement les cérémonies coutumières kanak (danse du «pilou»).

Au regard des attentes générées par cette célébration, cette cérémonie peut apparaître comme particulièrement modeste. Si cela peut être expliqué en partie par les restrictions budgétaires dont souffre le centre, la modestie de ce spectacle couplée à la diminution progressive des fréquentations ces dernières années font néanmoins émerger une série de questions. Ainsi, alors que le centre s'est ouvert aux différentes communautés depuis 2012, le résultat final du spectacle donne à voir des communautés divisées, qui ne s’influencent pas et qui demeurent ancrées dans leurs traditions. Cette situation traduit-elle son impossibilité à incarner les enjeux du destin commun, tout en affirmant son ancrage kanak? Illustre-t-elle son incapacité à se projeter dans le futur, à l'heure où se joue l'indépendance de l'archipel ? Ou témoigne-t-elle de sa difficulté à encourager et soutenir la création d'une identité culturelle calédonienne?

Indépendamment des réponses que l'on peut apporter à ces questions, l'histoire du centre culturel Tjibaou nous rappelle surtout la dépendance des musées aux redéfinitions constantes des intérêts sociaux, culturels et politiques de leur contexte. En effet, si cette institution a vu le jour à un moment particulier où les tensions entre les différentes communautés étaient au plus haut et l'avenir de la Nouvelle-Calédonie, incertain, le paysage culturel et social calédonien a bien changé depuis les années 1980. La sortie de l'Accord de Nouméa, l'émergence d'un nouveau cycle politique tourné vers l'horizon référendaire et enfin le retrait de la scène politique de la génération des signataires des Accords de Matignon sont autant de facteurs qui fragilisent la légitimité du centre en tant que symbole du «destin commun ». A cela s'ajoute l'émergence d'une nouvelle génération, désireuse de créer de nouveaux référents au-delà du centre culturel Tjibaou, institution trop européanisée qui porte en elle de nombreux évènements du passé encore douloureux.

Malgré ces nombreuses questions, ces difficultés ainsi que les critiques qui ont pu lui être adressées, il n'en reste pas moins que cet établissement a permis à des populations de se connaître, de développer leurs pratiques culturelles mais aussi d'insuffler un véritable élan de réflexion sur les symboles culturels du destin commun. Ainsi, indépendamment de son futur, le centre culturel Tjibaou a incontestablement contribué à poser les premières pierres de « la grande case du pays de demain »(Carteron, 2012, p. 49). À la société néocalédonienne désormais de décider si elle souhaite continuer de la bâtir sous 
cette forme, ou si, dans sa quête d'avenir, avec ou sans la France, elle souhaite lui donner de nouveaux sens.

\section{Références}

ADCK-Centre culturel Tjibaou (2015). Rapport d'activité. [Document inédit]. ADCK-Centre culturel Tjibaou (2016). Rapport d'activité. [Document inédit].

Agence de développement de la culture kanak (1998). Le Centre culturel Tjibaou.

Agence de développement de la culture kanak (2017). Adck. [Présentation]. Page consultée le 13 mai 2021, au http://www.adck.nc/presentation/ le-centre-culturel-tjibaou/presentation

Antic-Martin, C., Perin, L., Mannevy, C., \& Detcheverry, G. (2021, 30 janvier). Centre Culturel Tjibaou : la grande case du Sud inaugurée ce samedi. France Info. Page consulté le 15 juin 2021, au https://lalere.francetvinfo. $\mathrm{fr} /$ nouvellecaledonie/centre-culturel-tjibaou-la-grande-case-du-sud-inauguree-ce-samedi-921649.html

Bensa, A. (2000). Ethnologie et architecture. Le Centre Tjibaou, une réalisation de Renzo Piano. Adam Biro.

Bergeron, Y. (2019). Musées et patrimoines au Québec: Genèse et fondements de la muséologie nord-américaine. Hermann.

Bertin, M. (2019). Archives délaissées, archives retrouvées, archives explorées : Les fonds calédoniens pour l'étude du patrimoine kanak dispersé. Cahiers de l'École du Louvre, 14. https://doi.org/10.4000/cel.3737

Bertin, M. (2020). Le futur de la tradition : Quelle muséologie pour les musées nationaux du Pacifique Sud ? ICOFOM Study Series, 48(1), 95-108.

Brown, P. (2002). Alban Bensa's ethnologie et architecture. Contemporary Pacific, $14,281-84$.

Carteron, B. (2012). Le Mwâ Kââ, vers la manifestation d'une appartenance commune en Nouvelle-Calédonie? Journal de la Société des Océanistes, 134, 45-60.

Da Ros, D. L. (2010). L'esprit danse en Nouvelle-Calédonie, Mwà Véé, 70, 52-60.

Dubois, M. (2014). «Kanak, l'art est une parole », une pierre à l'édifice du «destin commun?» [Mémoire de stage non publié]. Ecole du Louvre.

Dussy, D. (2003). Le Centre Culturel Tjibaou, Nouvelle-Calédonie. [Rapport de mission]. Page consultée le 18 juin 2021, au https://halshs.archives-ouvertes.fr/halshs-00004147/document 
Guiart, J. (1996). Réflexion sur le concept de culture appliqué au Pacifique Sud. Études Mélanésiennes, 30, 33-59.

Graille, C. (2015). Des militants aux professionnels de la culture: Les représentations de l'identité kanak en Nouvelle-Calédonie (1975-2015). [Thèse de doctorat non publiél. Université Paul-Valéry Montpellier 3.

Graille, C. (2018). Passions identitaires et communauté de destin : une utopie calédonienne. Journal de la Société des Océanistes, 147, 351-364.

Healy, C., \& Witcomb, A. (Eds). (2006). South Pacific museums: Experiments in culture. Monash University Press.

Kaplan, F. E. S. (Ed.) (1994). Museums and the making of 'ourselves'. The role of objects in national identity. Leicester University Press.

Kasarhérou, E. (1999). Le Centre culturel Tjibaou : Entre Kanak et Calédoniens: Entretien avec Emmanuel Kasarhérou. Ethnologie française, 29(3), 437-444.

Kasarhérou, E. (2011). Le centre culturel Tjibaou, symbole identitaire de la Nouvelle-Calédonie? Dans J.-Y. Faberon, V. Fayaud \& J.-M. Regnault (Eds.), Destin des collectivités politiques d'Océanie: Peuples, populations, nations, États, territoires, pays, patries, communautés, frontières (pp. 697-702). Presses Universitaires d'Aix-Marseille.

Macdonald, S., \& Fyfe, G. (1996). Theorizing museums: Representing identities and diversity in a changing world. Blackwell.

McCarthy, C. (2018). Te Papa: Reinventing New Zealand's National Museum 19982018. Te Papa Press.

Message, K. (2006). Contested sites of identity and the cult of the new : The Centre Culturel Tjibaou and the constitution of culture in New Caledonia. ReCollections: Journal of the National Museum of Australia, 1(1), 7-28.

Morphy, H. (2017). Encounters at the National Museum of Australia: A moment in an ongoing process of engagement. International Journal of Heritage Studies, 23(9), 875-878.

Musée maritime de Nouvelle-Calédonie (2019). L'île de Lumière, l'engagement humanitaire d'un navire calédonien. Page consultée le 21 juin 2021, au https:// museemaritime.nc/actualites/expositions-temporaires/243-1-ile-de-lumiere-1-engagement-humanitaire-d-un-navire-caledonien

République française (1988). Accords de Matignon-Oudinot, accords intervenus le 26 juin 1988 sur la Nouvelle-Calédonie. Page consulté le 13 juin 2021, au http://www.mncparis.fr/uploads/accords-de-matignon_1.pdf

République française (1998). Déclaration de M. Lionel Jospin, Premier ministre, sur lidentité culturelle canaque, et notamment la vocation du Centre culturel Tjibaou à offrir un lieu de dialogue et d'échanges avec les cultures océaniennes, Nouméa le 4 mai 1998. Page consultée le 15 mai 2021, au https://www. 
vie-publique.fr/discours/139292-declaration-de-m-lionel-jospin-premierministre-sur-lidentite-cultur

Sand, C., Bolé, J., \& Ouetcho, A. (2003). Les aléas de la construction identitaire multi-ethnique en Nouvelle-Calédonie : Quel passé pour un avenir commun ?: Nouvelle-Calédonie : 150 ans après la prise de possession. Journal de la Société des océanistes, 117, 147-169.

Tjibaou, M. C. (1995). Plantation du premier arbre sur le site du Centre culturel Jean-Marie Tjibaou: Discours de Mme Marie-Claude Tjibaou, présidente de l'A.D.C.K. Mwà Véé, 8, 71-73.

Trépied, B. (2013). La décolonisation sans l'indépendance? Sortir du colonial en Nouvelle-Calédonie (1946-1975). Genèses, 91(2), 7-27.

Van Geert, F. (2020). Du musée ethnographique au musée multiculturel: Chronique d'une transformation globale. La documentation française.

Waïa, N. (2008). Nicola Waïa: Journaliste, militante, chargée de mission. Mwá Véé, 60, 14-16. 